Gut, 1984, 25, 491-499

\title{
Effect of intrajejunal acidity on lipid digestion and aqueous solubilisation of bile acids and lipids in health, using a new simple method of lipase inactivation
}

\author{
P L ZENTLER-MUNRO, D R FINE, W J F FITZPATRICK, \\ AND T C NORTHFIELD \\ From the Norman Tanner Gastroenterology Unit, St James' Hospital, and Department of Medicine, \\ St George's Hospital Medical School, London
}

SUMMARY We have investigated whether acid-mediated bile acid precipitation, pancreatic enzyme inactivation, and fatty acid partitioning occur in health when intraluminal $\mathrm{pH}$ falls below 5. In order to assess lipolysis and aqueous solubilisation of lipid, we first developed a new technique for inactivating lipase in jejunal aspirate (acid inactivation), and showed it to be more effective and simpler than the established technique (heat inactivation). We then studied 14 healthy subjects, aspirating jejunal content for three hours after a liquid meal, and pooling according to $\mathrm{pH}$. Eighteen per cent of the total aspirate was collected at $\mathrm{pH}<5$ compared with $56 \%$ at $\mathrm{pH}>6(\mathrm{p}<0 \cdot 01)$. Forty eight per cent of the bile acids were precipitated at $\mathrm{pH}<5$ compared with $18 \%$ at $\mathrm{pH}>6(\mathrm{p}<0.01)$, leading to a reduction in aqueous phase bile acid concentration at low $\mathrm{pH}(2.1 \mathrm{mmol} / \mathrm{l}$ at $\mathrm{pH}<5$ vs $5.8 \mathrm{mmol} / \mathrm{l}$ at $\mathrm{pH}>6, \mathrm{p}<0.01)$. Lipase activity was reduced at low $\mathrm{pH}(133 \mathrm{IU} / \mathrm{l}$ at $\mathrm{pH}<5$ vs $182 \mathrm{IU} / \mathrm{l}$ at $\mathrm{pH}>6, \mathrm{p}<0 \cdot 01)$, leading to reduced lipolysis at low $\mathrm{pH}(14 \%$ at $\mathrm{pH}<5$ vs $32 \%$ at $\mathrm{pH}>6, \mathrm{p}<0 \cdot 01)$. Aqueous phase lipid concentration was reduced at low $\mathrm{pH}(3.5 \mathrm{mmol} / \mathrm{l}$ at $\mathrm{pH}<5$ vs $12.5 \mathrm{mmol} / \mathrm{l}$ at $\mathrm{pH}>6, \mathrm{p}<0.01)$. This reduction was less dependent on bile acid precipitation than on lipase inactivation and fatty acid partitioning. We conclude that intraluminal acidity influences aqueous solubilisation of bile acids and lipid in health.

Maintenance of intraluminal $\mathrm{pH}$ near neutrality during digestion of food is important for several reasons. The in vitro activity of the three major pancreatic enzymes - lipase, trypsin, and amylase decreases markedly with $\mathrm{pH} .{ }^{12}$ Glycine conjugated bile acids precipitate out of aqueous solution below pH 5, whereas taurine conjugated bile acids precipitate only below $\mathrm{pH} 2 .^{3}$ The partitioning of fatty acids into the aqueous phase in vitro also decreases markedly as the $\mathrm{pH}$ is reduced below $6 .^{4}$

The in vivo effects of jejunal hyperacidity on fat digestion have been shown in a patient with Zollinger-Ellison syndrome. ${ }^{5}$ Greater precipitation of glycine conjugated bile acid occurred in jejunal samples of low $\mathrm{pH}$, while lipase was $50 \%$ inactivated below $\mathrm{pH}$ 5. Bile acid precipitation and lipase inactivation together led to reduced solubilisation of

Address for correspondence: Dr T C Northfield. Department of Medicine. St George's Hospital Medical School, Cranmer Terrace, London SW17 0RE. Received for publication 12 August 1983 lipid in the aqueous phase.

Early studies of intraluminal digestion in health showed that the $\mathrm{pH}$ of postprandial samples aspirated from the duodenum was always above $5^{6-8}$ suggesting that bile acid precipitation and lipase inactivation would not occur. $\mathrm{pH}$ probe studies in health, however, have shown that duodenal $\mathrm{pH}$ falls below 5 for about one third of a 100 minute postprandial period. ${ }^{9}$ The physiological effect of this has not been studied previously. The purpose of the current study was to determine whether acid mediated bile acid precipitation and lipase inactivation occur in health, and if so, whether they affect lipid solubilisation. The study involved the comparison of pancreatic enzyme concentration, bile acid precipitation, lipolysis and lipid solubilisation between samples aspirated at different $\mathrm{pHs}$. To facilitate this comparison, samples were pooled according to their $\mathrm{pH}$ in three $\mathrm{pH}$ pools: $\mathrm{pH}<5, \mathrm{pH}$ $5-6$, and $\mathrm{pH}>6$. 
In order to investigate lipid digestion and solubilisation in intestinal contents it is essential to arrest lipolysis in samples immediately after aspiration, as lipolysis proceeds rapidly at room temperature. ${ }^{10} 11$ Most investigators have used the method of heat inactivation at $70^{\circ} \mathrm{C}$ first described by Hofmann and Borgström. ${ }^{11}$ Although this method completely inactivates lipase, it has been found to lead to a $46 \%$ increase in fatty acid concentration as lipolysis is accelerated during the time taken for the sample to reach $70^{\circ} \mathrm{C} .^{12}$ This would lead to an artefactual increase in lipolysis and aqueous phase lipid concentration. The method becomes cumbersome when large samples of varying volume are aspirated, as numerous small aliquots of equal volume collected at one to two minute intervals must be heated separately in order to achieve a rapid and constant rate of heat transfer to the samples. ${ }^{11}$ We therefore decided to develop a new technique of lipase inactivation exploiting the fact that lipase is irreversibly inactivated at $\mathrm{pH} 3^{5}$ while bile acid precipitation $^{5}$ and fatty acid protonation ${ }^{4} 13$ are reversible. In this method, aspirates destined for lipid analyses are adjusted to $\mathrm{pH} 3$ immediately after collection by addition of acid, and restored to their original $\mathrm{pH}$ immediately before analysis by addition of an equivalent amount of alkali. Aspirates destined for enzyme and bile acid analyses are not treated. In this report we describe the validation of this method of inactivating lipase and its application to the study of healthy subjects.

\section{Methods}

\section{SUBJECTS}

The subjects were adults in good general health attending a gastroenterology clinic with non-specific abdominal pain. Routine tests including upperintestinal endoscopy, oral cholecystography, barium studies, and a Lundh test of pancreatic function were performed where appropriate and were normal. These subjects were considered suitable for the study as they were not suffering from any disease known to affect the variables under investigation. All subjects gave permission for the study according to the declaration of Helsinki. The protocol was approved by the local hospital ethical committee on 4th May 1977. The experiment involved a radiation exposure of $100 \mathrm{mrad}$ to the whole body and 30 mrad to the bone marrow. Permission was therefore refused to study asymptomatic medical staff or students, as exposure additional to that encountered in the course of their duties could not be justified. Women were studied within 10 days of menstruation. The new technique of lipase inactivation was validated in two experiments involving 14 subjects.
The technique was then applied to 14 different subjects studied in the main investigation (11 men and three women; average age 32 years, average weight $68 \mathrm{~kg}$ ).

\section{EXPERIMENTAL METHODS: VALIDATION OF TECHNIQUE FOR LIPASE INACTIVATION}

This experiment was performed to compare the effects of the conventional heat inactivation technique and of our acid inactivation technique on lipolysis and bile acid precipitation. Six subjects were involved in the first part of the experiment, and eight in the second.

\section{Intubation and meal}

After an overnight fast, a double lumen weighted tube (internal diameter $4 \mathrm{~mm}$ ) was passed through the nose so that the tip lay approximately 6 inches beyond the duodenojejunal flexure under fluoroscopic control; its position was confirmed at the end of the test. The resting contents of the duodenum were aspirated and discarded, and the patient drank a Lundh type liquid test meal containing $40 \mathrm{~g}$ dextrose, $15 \mathrm{~g}$ skimmed milk powder (Casilan) and $2.5 \mathrm{~g}$ polyethylene glycol 4000 (PEG), dissolved in $230 \mathrm{ml}$ water and thoroughly mixed with $18 \mathrm{~g}$ corn oil.

\section{Sampling (Fig. 1)}

Whenever the flow of fluid from the tube was sufficiently rapid that at least $20 \mathrm{ml}$ could be collected within a few seconds, this sample was used for validation of the technique. After mixing, a $1 \mathrm{ml}$ aliquot (A) was extracted within 20 seconds for analysis of fatty acid concentration. This sample was considered to be the most accurate estimate of the intraluminal concentration before artefactual lipolysis. A $7 \mathrm{ml}$ aliquot (B) in an Erlenmeyer flask was swirled by hand in a $70^{\circ} \mathrm{C}$ water bath for one minute and then left in the water bath for a further nine minutes exactly as described by Hofmann and Borgström. ${ }^{11}$ An $11 \mathrm{ml}$ aliquot (C) was immediately adjusted to $\mathrm{pH}<3$ using $1 \mathrm{~N}-\mathrm{HCl}$ and kept at $0^{\circ} \mathrm{C}$ in crushed ice. A $1 \mathrm{ml}$ aliquot (D) was stored untreated after immediate measurement of its $\mathrm{pH}$. All aspirate not used for this purpose was pooled and analysed for trypsin and lipase as a test of pancreatic function.

\section{Laboratory procedures (Fig. 1)}

On arrival in the laboratory three hours later, $1 \mathrm{ml}$ of B was extracted for fatty acid and $5 \mathrm{ml}$ ultracentrifuged overnight at $100000 \mathrm{~g}, 37^{\circ} \mathrm{C}$; the aqueous phase was removed in its entirety, mixed and analysed for bile acid concentration. Aliquot $\mathrm{C}$ was restored to its original $\mathrm{pH}$ (as recorded for $\mathrm{D}$ ) by gradual addition of $1 \mathrm{~N}-\mathrm{NaOH}$ during thorough 


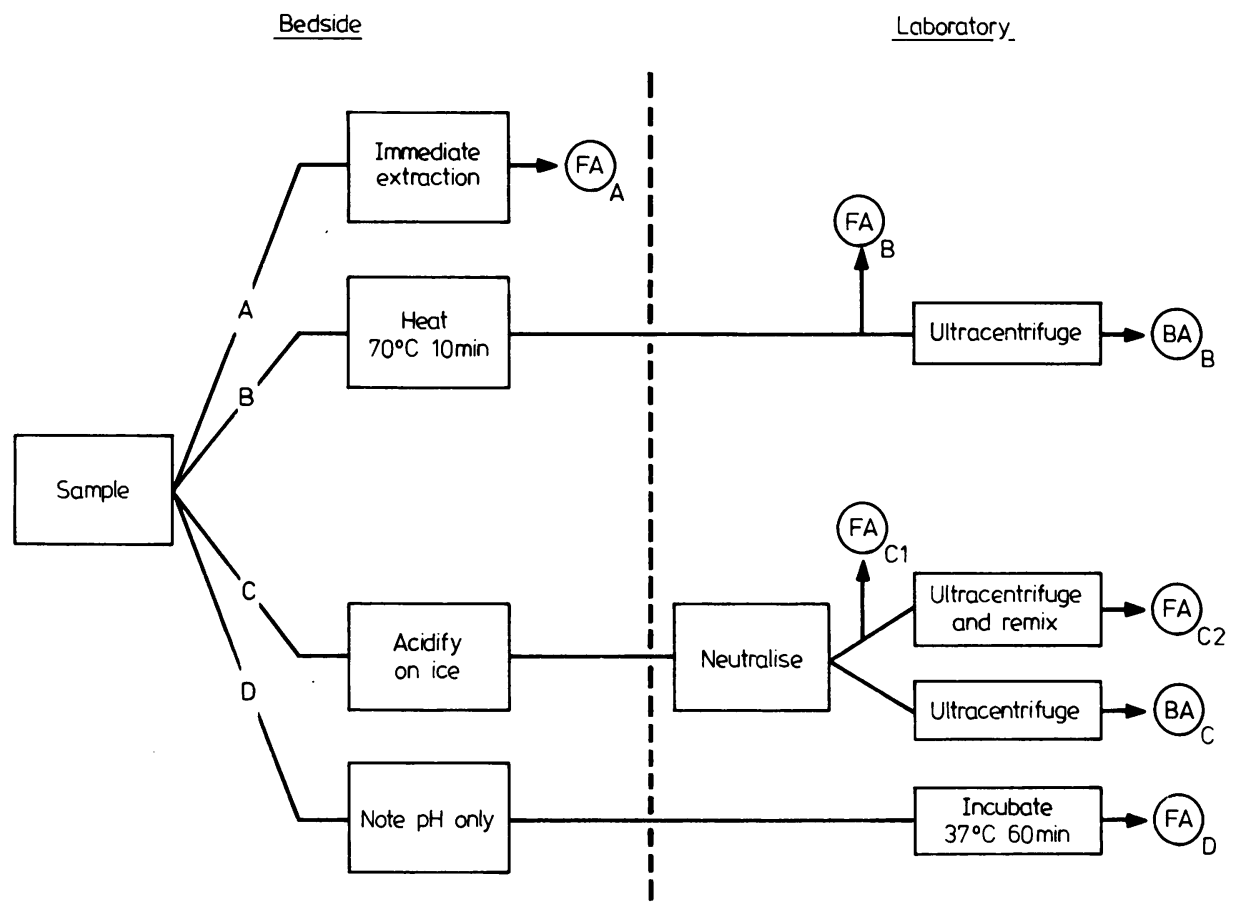

Fig. 1 Processing of samples of duodenal aspirate in validation experiment: acid inactivation of lipase.

mixing and its $\mathrm{pH}$ rechecked after final mixing. One millilitre was extracted for fatty acid $\left(\mathrm{C}_{1}\right)$ and two $5 \mathrm{ml}$ aliquots in separate tubes were loaded into an ultracentrifuge precooled to $0^{\circ} \mathrm{C}$. Immediately before starting the motor, the temperature control was reset to $37^{\circ} \mathrm{C}$. The aliquots were centrifuged at $100000 \mathrm{~g}$ overnight, the temperature rising to $37^{\circ} \mathrm{C}$ over the first two to three hours. The aqueous phase was removed from one tube, mixed, and analysed for bile acid concentration. The other tube was mixed thoroughly to recombine oil phase, aqueous phase and precipitate, and extracted for fatty acid $\left(C_{2}\right)$. D was incubated at $37^{\circ} \mathrm{C}$ for one hour and then extracted for fatty acid.

A separate experiment was then performed to check that cooling samples did not irreversibly alter the partitioning of lipids after rewarming. In eight different subjects, postprandial chyme was collected at $37^{\circ} \mathrm{C}$ and stirred at this temperature for three hours, in order to ensure that lipolysis had reach equilibrium. A $10 \mathrm{ml}$ sample of this fluid was then acidified as in $\mathrm{C}$, and divided in two. Half was cooled to $0^{\circ} \mathrm{C}$ until being restored to its original $\mathrm{pH}$ and ultracentrifuged overnight at $100000 \mathrm{~g}, 37^{\circ} \mathrm{C}$. The other half was held at $37^{\circ} \mathrm{C}$, then stored and ultracentrifuged in the same machine. Aqueous phases were separated and analysed for fatty acid, and for total saponifiable lipid. All fatty acid estimations were performed together on the day following collection (using 0.01 M tetra-n-butyl ammonium hydroxide). The results were corrected for dilution by the volumes of acid and alkali added in initial treatment.

\section{EXPERIMENTAL METHODS: INVESTIGATION OF HEALTHY SUBJECTS \\ Intubation and meal were as described above.}

\section{Sampling (Fig. 2)}

As much jejunal content as possible was collected continuously by siphonage and syringe aspiration into ice cooled $10 \mathrm{ml}$ measuring cylinders. The second lumen of the tube was used as an air vent. Each time sufficient sample was obtained (c. $3 \mathrm{ml}$ ), its $\mathrm{pH}$ was measured immediately with a glass electrode. It was then mixed and divided in two. Half was assigned to the appropriate one of three $\mathrm{pH}$ pools $(\mathrm{pH}<5, \mathrm{pH} 5-6, \mathrm{pH}>6)$ and the pools maintained at a $\mathrm{pH}$ below 3 by the addition, after each sample, of about $0.1 \mathrm{ml} 1 \mathrm{~N}-\mathrm{HCl}$ per $3 \mathrm{ml}$ of sample. The other half was assigned to one of three similar $\mathrm{pH}$ pools which were not acidified. All pools were kept at $0^{\circ} \mathrm{C}$ in crushed ice. At the end of each hour, the $\mathrm{pH}$ of each untreated pool was noted, and 


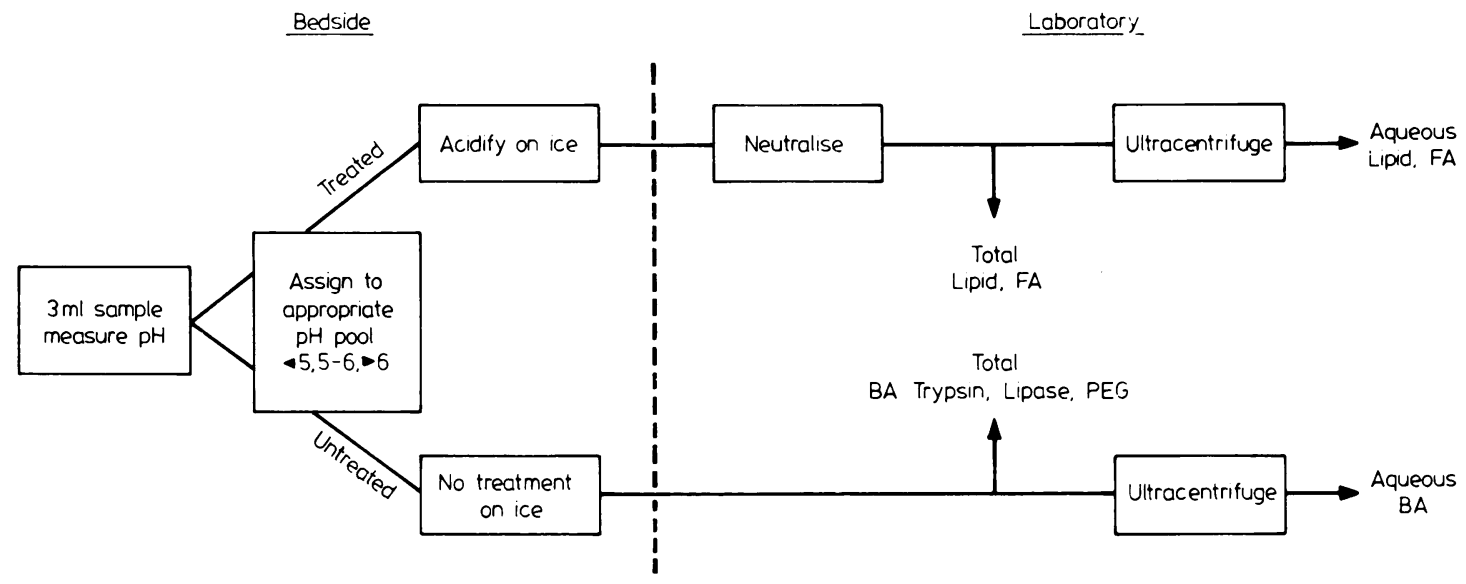

Fig. 2 Processing of samples of duodenal aspirate in main experiment: investigation of healthy subjects.

new pools started. The test was concluded three hours after the administration of the meal. There could thus be a maximum of three treated and three untreated pools for each of three hours - 18 in total.

\section{Laboratory procedures (Fig. 2)}

Treated pools: on the afternoon of collection, each treated pool was restored to its original $\mathrm{pH}$ (the $\mathrm{pH}$ recorded for the corresponding untreated pool) with $1 \mathrm{~N}-\mathrm{NaOH}$. An aliquot was extracted immediately in ethanol-toluene for titration of total fatty acid concentration. ${ }^{14}$ A $5 \mathrm{ml}$ aliquot was loaded into an ultracentrifuge precooled to $0^{\circ} \mathrm{C}$, and centrifuged overnight after resetting the temperature control to $37^{\circ} \mathrm{C}$ as described above. The aqueous phase was removed in its entirety, mixed, and an aliquot extracted and titrated for aqueous phase fatty acid concentration. ${ }^{14}$ Total and aqueous phase saponifiable lipids were extracted and titrated similarly after alkaline hydrolysis in $5 \%$ ethanolic $\mathrm{KOH}$. All titrations were performed together on the day after collection and the results corrected for dilution as described above. Both fatty acid and total lipid concentrations are expressed in terms of mmol of fatty acid titrated. Untreated pools: on the afternoon of collection, $5 \mathrm{ml}$ aliquots of each pool were ultracentrifuged similarly. The aqueous phase was removed in its entirety, mixed and stored with the uncentrifuged pools at $-20^{\circ} \mathrm{C}$. Total and aqueous phase bile acid concentrations were later determined enzymatically. ${ }^{15}$ Trypsin, ${ }^{16}$ lipase,${ }^{17}$ and $\mathrm{PEG}^{18}$ concentrations were measured in the uncentrifuged pools.

MATHEMATICAL ANALYSIS

For each subject comparison between the $\mathrm{pH}<5$.
$\mathrm{pH} 5-6$, and $\mathrm{pH}>6$ pools was made after mathematically pooling the separate hourly pools for each $\mathrm{pH}$. The three hourly pools were compared after similarly pooling the separate $\mathrm{pH}$ pools for each hour. The 'overall mean' was calculated by mathematically pooling all the separate pools. This method takes into account the widely differing volumes of each pool; individual pools of small volume contribute proportionately little to the $\mathrm{pH}$ means, hourly means and overall mean. The pHs recorded for each pool were converted to hydrogenion concentration in order to calculate the $\mathrm{pH}$ of the hourly pools.

Derivations were calculated as follows, before pooling:

$$
\begin{aligned}
& \text { Lipolysis }(\%)=(\text { total fatty acid/total lipid }) \times \\
& 100 \\
& \text { Aqueous phase 'glyceride' (mmol/1) }=\text { aqueous } \\
& \text { phase saponifiable lipid }- \text { aqueous phase fatty } \\
& \text { acid } \\
& \text { Bile acid precipitation }(\%)=(\text { total }- \text { aqueous } \\
& \text { phase bile acid/total bile acid) } \times 100 \\
& \text { Fatty acid solubilisation in aqueous phase }(\%) \\
& =(\text { aqueous phase fatty acid/total fatty acid }) \times \\
& 100 \text {. }
\end{aligned}
$$

The calculation of bile acid precipitation and fatty acid solubilisation assumes the oil phase and precipitate to have negligible volume: where this was not so. values less than $0 \%$ or greater than $100 \%$ may therefore occur. The formula for pooling was as follows:

$$
\text { Pooled value }=\Sigma(\mathrm{CV}) / \Sigma \mathrm{V} \text {. }
$$

where for each pool to be pooled,

$\mathrm{C}=$ concentration or derivation, and $\mathrm{V}=$ volume . 


\section{STATISTICAL ANALYSIS}

pH pools

The hypothesis that values for the $\mathrm{pH}<5$ and $\mathrm{pH}>6$ pools were equal was tested using the Wilcoxon signed rank rest. ${ }^{19}$ The $\mathrm{pH}$ 5-6 pool was not examined statistically. Similarity between all three $\mathrm{pH}$ pools was tested using the Friedmann two way analysis of variance by ranks. ${ }^{19}$

\section{Hourly pools}

We had no hypothesis to predict the behaviour of the hourly pools. In order to avoid the error of 'data snooping ${ }^{19} \mathrm{pH}$ values in the three hourly pools were compared using the Friedmann two way analysis of variance by ranks; application of Wilcoxon's critical range method for multiple comparisons ${ }^{19}$ showed a significant difference in $\mathrm{pH}$ between first and second hour. We then examined differences between the first and second hour for other values using the Wilcoxon signed rank test.

\section{Results}

\section{VALIDATION OF TECHNIQUE}

Seventeen samples were obtained from the six subjects. Conventional heat inactivation (B) caused a $12 \pm 4 \%$ (mean $\pm \mathrm{SEM}$ ) rise in fatty acid over the aliquot extracted immediately (A), while acid inactivation $\left(C_{1}\right)$ caused only a $3 \pm 2 \%$ rise. indicating that acid inactivation caused significantly less artefactual lipolysis than heat activation $(p<0.01)$. Fatty acid in $C_{2}$ was $2 \pm 4 \%$ lower than in $\mathrm{C}_{1}$ (NS) indicating that lipolysis did not resume after neutralisation and ultracentrifugation overnight at $37^{\circ} \mathrm{C}$. Aqueous phase bile acid was $5 \pm 4 \%$ higher after heat inactivation than acid inactivation (NS) suggesting that our technique gives results comparable with those of the conventional method. Fatty acid in D was increased by at least $20 \%$ in all cases, confirming that there was capacity for further lipolysis if permitted.

In the second experiment eight samples were obtained from eight subjects. The aqueous phase fatty acid concentrations in the samples cooled to $0^{\circ} \mathrm{C}$ were similar to those in the samples kept at $37^{\circ} \mathrm{C}$ $(2.60 \pm 0.80$ vs $2.69 \pm 0.63 \mathrm{mmol} / 1$. NS), as were the aqueous phase total lipid concentrations (3.97 $\pm 1 \cdot 10$ $\mathrm{mM} / \mathrm{l}$ vs $4 \cdot 11 \pm 0 \cdot 87$, NS). This suggests that the cooling of samples to $0^{\circ} \mathrm{C}$ did not irreversibly alter the distribution of fatty acid and lipid between aqueous and oil phases.

\section{INVESTIGATION OF HEALTHY SUBJECTS COMPARISON OF PH POOLS (Table 1) $p H$} Eighteen per cent of the total PEG aspirated was recovered at the critical $\mathrm{pH}<5$, significantly less than at $\mathrm{pH}>6$. The proportions of lipid aspirated at each $\mathrm{pH}$ paralleled those of PEG. This suggests that the $\mathrm{pH}$ effects discussed below apply equally to the lipid and aqueous portions of the meal. Polyethylene glycol and total lipid concentrations were similar at each $\mathrm{pH}$ suggesting that gastric contents and pancreato-biliary fluid had mixed completely before entering the jejunum. and that the differences in concentration of other substances at each $\mathrm{pH}$ were not caused by differences in dilution.

\section{Pancreatic enzymes}

The overall mean trypsin for each patient (range $12-23 \mathrm{IU} / \mathrm{ml}$ ) was within the accepted normal range..$^{20}$ (A normal range for lipase using this

Table 1 Healthy subjects - comparison of $p H$ pools

\begin{tabular}{|c|c|c|c|c|}
\hline & $p H<5$ & pH 5-6 & $p H>6$ & $\begin{array}{l}\text { Significance } \\
\text { pH<5 v's } \mathrm{pH}>6\end{array}$ \\
\hline PEG recoverv (\% of total recovered) & $17 \cdot 7 \pm 4 \cdot 8$ & $26 \cdot 6 \pm 4 \cdot 3$ & $55 \cdot 7 \pm 7 \cdot 3$ & $\mathrm{p}<0.01$ \\
\hline Lipid recovery ( $\%$ of total recovered) & $18 \cdot 6 \pm 5 \cdot 3$ & $24 \cdot 5 \pm 4 \cdot 2$ & $57.0 \pm 6.9$ & $\mathrm{p}<0.01$ \\
\hline PEG concentration $(g / l)$ & $2 \cdot 5 \pm 0 \cdot 4$ & $2 \cdot 9 \pm 0 \cdot 3$ & $2 \cdot 7 \pm 0 \cdot 2$ & NS $\div$ \\
\hline Trypsin (IU/1) & $14 \cdot 7 \pm 1 \cdot 5$ & $17 \cdot 2 \pm 0 \cdot 8$ & $19 \cdot 1 \pm 1 \cdot 5$ & $\mathrm{p}<0.05$ \\
\hline Lipase (U/1) & $133 \pm 9$ & $165 \pm 7$ & $182 \pm 11$ & $\mathrm{p}<0.01$ \\
\hline Total lipid (mmol/l) & $36 \cdot 4 \pm 9 \cdot 2$ & $34 \cdot 5 \pm 6 \cdot 4$ & $34 \cdot 6 \pm 3 \cdot 6$ & NS ${ }^{+}$ \\
\hline Total fatty acid $(\mathrm{mmol} / \mathrm{l})$ & $2 \cdot 6 \pm 0 \cdot 6$ & $4.8 \pm 0.6$ & $10.6 \pm 1.9$ & $\mathrm{p}<0.01$ \\
\hline Lipolysis (\%) & $13 \cdot 5 \pm 3 \cdot 9$ & $19 \cdot 6 \pm 2 \cdot 9$ & $32 \cdot 4 \pm 3 \cdot 2$ & p $<0.01$ \\
\hline Total bile acid $(\mathrm{mmol} / \mathrm{l})$ & $4 \cdot 1 \pm 0 \cdot 4$ & $4.6 \pm 0 \cdot 4$ & $6.9 \pm 0.7$ & $\mathrm{p}<0.01$ \\
\hline Aqueous phase bile acid $(\mathrm{mmol} / \mathrm{l})$ & $2 \cdot 1 \pm 0 \cdot 3$ & $3.5 \pm 0.4$ & $5 \cdot 8 \pm 0 \cdot 8$ & $\mathrm{p}<0.01$ \\
\hline Bile acid precipitation ( $\%$ ) & $47.9 \pm 3.5$ & $22 \cdot 7 \pm 4 \cdot 5$ & $17 \cdot 6 \pm 3 \cdot 7$ & $p<0.01$ \\
\hline Aqueous phase lipid $(\mathrm{mmol} / \mathrm{l})$ & $3 \cdot 5 \pm 0 \cdot 4$ & $7 \cdot 2 \pm 1 \cdot 4$ & $12 \cdot 5 \pm 3 \cdot 1$ & $\mathrm{p}<0.01$ \\
\hline Aqueous phase fattv acid (mmol/l) & $0.4 \pm 0.2$ & $1.9 \pm 0.3$ & $7 \cdot 1 \pm 1 \cdot 8$ & $\mathrm{p}<0.01$ \\
\hline Proportion fatty acid in aqueous phase $(\%)$ & $13 \cdot 2 \pm 6 \cdot 0$ & $+1 \cdot 0 \pm 7 \cdot 5$ & $65 \cdot 0 \pm 10 \cdot 4$ & $p<0.01$ \\
\hline Aqueous phase glycerides $(\mathrm{mmol} / \mathrm{l})$ & $3 \cdot 1 \pm 0 \cdot 4$ & $5 \cdot 3 \pm 1 \cdot 4$ & $5 \cdot 4 \pm 1 \cdot 4$ & NS $\div$ \\
\hline
\end{tabular}

* Wilcoxon test. NS = Not significant. $\div$ No difference between any pools (Friedmann test). 
technique has not been previously described in the literature). The activities of trypsin and lipase were significantly lower at $\mathrm{pH}<5$ than $\mathrm{pH}>6$, but still within the normal range. The $\mathrm{pH} 5-6$ concentration was intermediate.

\section{Lipid digestion}

Total lipid concentration was similar at each $\mathrm{pH}$, but total fatty acid concentration and lipolysis were significantly lower at $\mathrm{pH}<5$ than at $\mathrm{pH}>6, \mathrm{pH} 5-6$ being intermediate.

\section{Bile acids}

Total bile acid concentration was slightly but significantly lower at $\mathrm{pH}<5$ than at $\mathrm{pH}>6$. Half of the available bile acid was precipitated at $\mathrm{pH}<5$, more than twice that at $\mathrm{pH}>6$. This was accompanied by a marked reduction in aqueous phase bile acid concentration at $\mathrm{pH}<5$, the concentration at $\mathrm{pH} 5-6$ again being immediate.

\section{Lipid solubilisation}

Both aqueous phase lipid and fatty acid concentrations were markedly lower at $\mathrm{pH}<5$ than at $\mathrm{pH}>6$. At $\mathrm{pH}<5$, only $13 \%$ of the available fatty acid was solubilised, one fifth of the value at $\mathrm{pH}>6$.

COMPARISON OF HOURLY POOLS (Table 2)

\section{Meal recovery}

An average of $30 \%$ of the PEG in the meal was recovered during the three hour study. Only $17 \%$ of the total PEG and $25 \%$ of the total lipid aspirated were recovered during the third hour, while only very small samples could be obtained at the end of the third hour. In a pilot study of six healthy subjects in which jejunal aspirate after an identical test meal was pooled at 15 minute intervals (unpublished), PEG concentration fell almost to zero by the end of the third hour (Fig. 3). These findings indicate that the whole of the meal was sampled during the three-hour study, and suggest that our extrapolation from PEG recovery to recovery of the aqueous portion of the meal is valid.

\section{Bile acids}

$\mathrm{pH}$ decreased significantly from the first to the second hour. This was accompanied by a significant increase in bile acid precipitation and corresponding decrease in aqueous phase bile acid concentration.

\section{Enzymes}

Concentrations of trypsin and lipase remained constant over the three hours, normal concentrations being maintained throughout the test.

\section{Lipid digestion and solubilisation}

Lipolysis and fatty acid concentration also remained constant from hour to hour. The proportion of fatty acid in the aqueous phase fell from the first to the second hour, corresponding to the increase in bile acid precipitation.

\section{Discussion}

\section{VALIDATION OF THE METHODS}

Our validation experiments have shown that addition of acid to intestinal aspirate, and subsequent neutralisation before analysis, arrests all lipolysis without altering bile acid distribution. Cooling of the acidified samples was essential for

Table 2 Healthy subjects - comparison of hourly pools

\begin{tabular}{|c|c|c|c|c|}
\hline & Ist hour & 2nd hour & 3rd hour & $\begin{array}{l}\text { Significance* } \\
\text { 1st hour vs } 2 \text { nd hour }\end{array}$ \\
\hline PEG recovery $(\%)$ & $48 \cdot 7 \pm 6 \cdot 7$ & $34 \cdot 1 \pm 4 \cdot 9$ & $17 \cdot 2 \pm 6 \cdot 1$ & $\mathrm{p}<0.05 \ddagger$ \\
\hline Lipid recovery $(\%)$ & $32 \cdot 8 \pm 3 \cdot 6$ & $42 \cdot 2 \pm 4 \cdot 3$ & $25 \cdot 0 \pm 4 \cdot 1$ & NSt \\
\hline PEG concentration $(g / l)$ & $3 \cdot 4 \pm 0 \cdot 4$ & $2 \cdot 6 \pm 0 \cdot 3$ & $1 \cdot 3 \pm 0 \cdot 3$ & $p<0.01 \ddagger$ \\
\hline $\mathrm{pH}$ & $6 \cdot 2 \pm 0 \cdot 2$ & $5 \cdot 3 \pm 0 \cdot 2$ & $5 \cdot 4 \pm 0 \cdot 2$ & $\mathrm{p}<0.05$ \\
\hline Total bile acid $(\mathrm{mmol} / \mathrm{l})$ & $7 \cdot 1 \pm 1 \cdot 1$ & $4 \cdot 9 \pm 0 \cdot 5$ & $5 \cdot 9 \pm 0 \cdot 6$ & $\mathrm{p}<0.05$ \\
\hline Aqueous phase bile acid $(\mathrm{mmol} / \mathrm{l})$ & $6 \cdot 1 \pm 1 \cdot 1$ & $3 \cdot 5 \pm 0.4$ & $4 \cdot 2 \pm 0 \cdot 6$ & $\mathrm{p}<0.01$ \\
\hline Bile acid precipitation $(\%)$ & $17 \cdot 6 \pm 4 \cdot 8$ & $29 \cdot 5 \pm 3 \cdot 0$ & $31 \cdot 4 \pm 4 \cdot 5$ & $\mathrm{p}<0.05$ \\
\hline Trypsin (IU/l) & $16 \cdot 8 \pm 2 \cdot 0$ & $19 \cdot 6 \pm 1 \cdot 2$ & $20 \cdot 6 \pm 2 \cdot 6$ & NS + \\
\hline Lipase (U/l) & $171 \pm 13$ & $172 \pm 10$ & $175 \pm 11$ & NS ${ }^{+}$ \\
\hline Total lipid (mmol/l) & $32 \cdot 1 \pm 5 \cdot 1$ & $44 \cdot 9 \pm 5 \cdot 9$ & $33 \cdot 8 \pm 4 \cdot 9$ & NS+ \\
\hline Total fatty acid $(\mathrm{mmol} / \mathrm{l})$ & $7 \cdot 5 \pm 3 \cdot 2$ & $10 \cdot 1 \pm 3 \cdot 4$ & $10 \cdot 9 \pm 1 \cdot 3$ & NS \\
\hline Lipolysis (\%) & $24 \cdot 9 \pm 4 \cdot 2$ & $26 \cdot 0 \pm 4 \cdot 2$ & $31 \cdot 1 \pm 2 \cdot 5$ & NSt \\
\hline Aqueous phase lipid (mmol/l) & $13 \cdot 7 \pm 5 \cdot 3$ & $8 \cdot 7 \pm 3 \cdot 6$ & $8 \cdot 0 \pm 1 \cdot 9$ & NSt \\
\hline Aqueous phase fatty acid $(\mathrm{mmol} / \mathrm{l})$ & $7 \cdot 2 \pm 3 \cdot 5$ & $4 \cdot 7 \pm 2 \cdot 8$ & $4.5 \pm 0.9$ & NSt \\
\hline Proportion fatty acid in aqueous phase (\%) & $74 \cdot 7 \pm 9 \cdot 8$ & $36 \cdot 5 \pm 8 \cdot 5$ & $42 \cdot 7 \pm 6 \cdot 4$ & $\mathrm{p}<0.01$ \\
\hline
\end{tabular}

* Wilcoxon test. NS = Not significant. $\quad+$ No difference between any pools (Friedmann test).

$\ddagger 1$ st $v$ s 3rd hour also significant (Friedmann + Wilcoxon critical range test). 


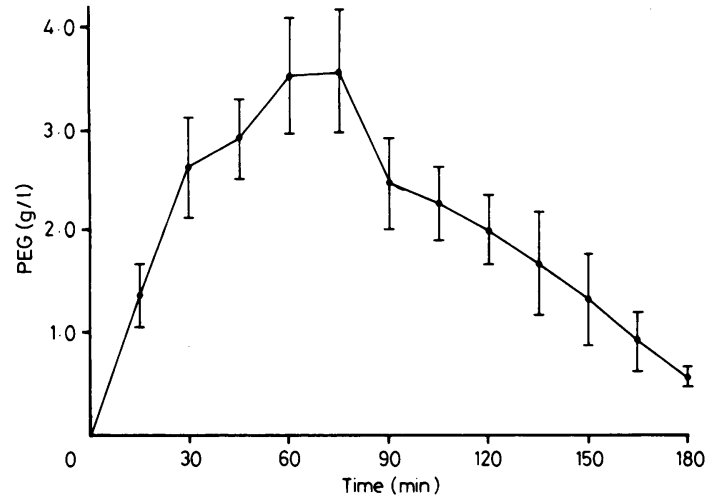

Fig. 3 Relationship between postprandial PEG concentration in duodenal aspirate and time in pilot study of six healthy subjects: PEG concentrations fell almost to zero by the end of the third hour.

this inactivation, but did not irreversibly alter the ultimate distribution of lipid between aqueous and oil phases at $37^{\circ} \mathrm{C}$. This technique of acid inactivation is less cumbersome than heat inactivation and reduces the artefactual lipolysis inherent in heat inactivation. ${ }^{12}$ Several investigators have simplified the original method of heat inactivation by pooling samples over $30^{521}$ or $45^{22}$ minutes before heating but this allows lipolysis to proceed at room temperature. In another study, aspirate was collected continuously into a vessel maintained at $70^{\circ} \mathrm{C}$ for at least 20 minutes, ${ }^{23}$ but this simplification may lead to increased phospholipolysis, as phospholipase activity is maintained at this temperature. ${ }^{24}$ In contrast, our method appears to arrest phospholipolysis, as the negligible rise in fatty acid concentration reflects both lipolysis and phospholipolysis phospholipolysis is known to be inhibited at $\mathrm{pH} 3 .^{24}$ Our results for lipolysis and lipid solubilisation in the upper jejunum are slightly lower than those found by others in health, 5232526 probably reflecting the improved efficacy of our method for lipase inactivation.

The use of a transpyloric tube to aspirate postprandial jejunal content does not alter gastric acid secretion or the rate of gastric emptying. ${ }^{27}$ The use of a liquid meal rather than a more physiological solid meal is convenient; solid meals elicit greater acid secretion, 28 and would therefore tend to increase the effects we have observed. The use of PEG as a non-absorbable marker of dilution for both the aqueous and lipid phases of intestinal content has been validated ${ }^{6}{ }^{29}$ but criticised. $^{30}$ In our study, the proportions of PEG at each pH paralleled those of lipid, suggesting that it was an adequate lipid marker for comparing $\mathrm{pH}$ pools. The total recovery of PEG over the three hour study period (mean 30\%) compares favourably with that obtained by other investigators. ${ }^{6}$

\section{APPLICATION TO HEALTHY SUBJECTS}

Several investigators have reported postprandial jejunal $\mathrm{pH}$ falling intermittently below 5 in health, but have not quantitated the amount of meal so affected. A study using a $\mathrm{pH}$ probe in the descending duodenum in healthy subjects reported $\mathrm{pHs}$ below 5 for $30 \%$ of a 100 minute postprandial period. ${ }^{9}$ Our findings of only $18 \%$ of the meal aspirated at $\mathrm{pH}<5$ probably reflects our more distal aspiration site, and also the fact that a minimum requirement of $3 \mathrm{ml}$ of aspirate to measure $\mathrm{pH}$ would tend to obscure extremes of $\mathrm{pH}$ in either direction.

The gradient of pancreatic enzyme activity with $\mathrm{pH}$ probably reflects intraluminal inactivation, as differences in dilution have been excluded by the similar PEG concentrations at each $\mathrm{pH}$. This interpretation is supported by the decreased lipolysis at low $\mathrm{pH}$, showing that the decrease in lipase activity exerted a functional effect on lipolysis.

We have shown a marked gradient of bile acid precipitation with $\mathrm{pH}$. The figure for $\mathrm{pH} 5-6$ is close to that for $\mathrm{pH}>6$, as would be expected from the in vitro observation that the critical $\mathrm{pHs}$ of precipitation for glycine conjugates are slightly below $5 .^{3}$ Bile acid precipitation resulted in a marked gradient of aqueous phase bile acid concentration with $\mathrm{pH}$; at $\mathrm{pH}<5$ only half the available bile acid was in aqueous solution and able to contribute to micelle formation. The finding of $18 \%$ bile acid precipitation at $\mathrm{pH}>6$, well above the critical $\mathrm{pH}$, suggests that binding of bile acid to food residue also reduces aqueous bile acid concentration. We have demonstrated a similar degree of binding to the protein content of the Lundh meal in vitro. ${ }^{31}$ Glycine conjugated bile acid remaining in solution at $\mathrm{pH}<5$ is likely to be reabsorbed in the jejunum by passive non-ionic diffusion ${ }^{32}$ further reducing intraluminal bile acid concentration. The reduction in total bile acid concentration at $\mathrm{pH}<5$ is unlikely to be caused by greater dilution by gastric acid, as PEG and total lipid concentrations did not vary with $\mathrm{pH}$. It is more likely to be because of precipitation of bile acid onto pieces of debris not recovered up the tube. The figure of $48 \%$ bile acid precipitation at $\mathrm{pH}<5$ may therefore be an underestimate.

Analysis of the experiment in relation to time, rather than $\mathrm{pH}$, supports our findings, as the results expressed as hourly pools were calculated quite independently of the $\mathrm{pH}$ of individual samples. The fall in $\mathrm{pH}$ in the second hour from 6.2 to 5.3 was associated with a significant increase in bile acid 
precipitation and fall in aqueous phase bile acid concentration, leading to a significant reduction in the proportion of fatty acid solubilised. We did not detect inactivation of trypsin or lipase accompanying this slight fall in $\mathrm{pH}$, and lipolysis remained constant.

Three $\mathrm{pH}$ dependent factors may reduce the digestion and solubilisation of non-polar dietry triglyceride at $\mathrm{pH}<5$ : (i) lipase inactivation reducing lipolysis; (ii) bile acid precipitation reducing solubilisation of the polar products of lipolysis (fatty acid and monoglyceride) into the aqueous phase; (iii) partitioning of protonated fatty acid into the oil phase at $\mathrm{pH}<6$, even in the presence of an adequate bile acid concentration. ${ }^{4}$ This possibility was not evaluated in studies showing a correlation between $\mathrm{pH}$ and lipid solubilisation in Zollinger-Ellison syndrome $e^{5}$ and pancreatic insufficiency. ${ }^{33}$ Our results can be used to separate all three $\mathrm{pH}$ effects. The marked $\mathrm{pH}$ gradients we found for aqueous phase lipid (total saponifiable) and fatty acid concentrations reflect the combined effect of all three factors. The gradient for the proportion of total fatty acid in the aqueous phase eliminates the effect of lipase inactivation and reflects only bile acid precipitation and fatty acid partitioning. To separate the contribution of these two factors in vivo is problematic since reduction of $\mathrm{pH}$ below 6.0 affects both simultaneously. Analysis of covariance, by removing variation between individuals, reveals a linear relationship between the proportion of fatty acid in the aqueous phase and bile acid precipitation (Fig. 4: $F=27 \cdot 7, p<0 \cdot 01$ ). The intercept of the

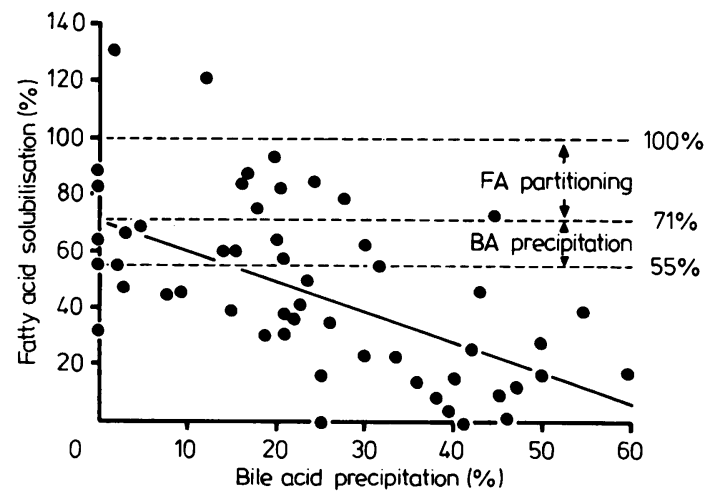

Fig. 4 Relationship between fatty acid solubilisation (adjusted for variation between individuals) and bile acid precipitation $(F=27 \cdot 7, p<0 \cdot 01)$. This demonstrates relative contribution of fatty acid partitioning and bile acid precipitation in limiting fatty acid solubilisation (overall mean fatty acid solubilisation observed $=55 \pm 7 \%$, fatty acid solubilisation at zero bile acid precipitation $=71 \pm 10 \%)$. regression line indicates that in the absence of bile acid precipitation $71 \cdot 2 \pm 10 \%$ of the fatty acid partitions into the aqueous phase. In the presence of bile acid precipitation the overall mean proportion of fatty acid actually in the aqueous phase was $54.7 \%$. Therefore, of the $45.3 \%$ of fatty acid not solubilised $28.8 \%(=100-71 \cdot 2)$ could be attributed to partitioning, and only $16.5 \%(=71 \cdot 2-54 \cdot 7)$ to bile acid precipitation. A similar process of elimination can be applied to aqueous phase glyceride, the other component of total lipid, which also showed a $\mathrm{pH}$ gradient (Table 1). As glycerides are not susceptible to $\mathrm{pH}$-dependent partitioning ${ }^{413}$ this gradient must be attributable to bile acid precipitation or lipase inactivation. The mean fall in aqueous phase gluceride concentration from $\mathrm{pH}>6$ to $\mathrm{pH}<5$ $(2.0 \pm 1.6 \mathrm{mM} / \mathrm{l})$ can be attributed entirely to lipase inactivation, as it is less than half the mean fall in total fatty acid concentration from $\mathrm{pH}>6$ to $\mathrm{pH}<5$ $(6.7 \pm 1.3 \mathrm{mM} / \mathrm{l})$ and lipolysis releases two moles of fatty acid for each mole of monoglyceride. Thus the fatty acid and glyceride data both concur that aqueous solubilisation of lipid at low $\mathrm{pH}$ in health is limited less by bile acid precipitation than by lipase inactivation and fatty acid partitioning.

We conclude that even in health a significant proportion of a meal passing down the upper jejunum is exposed to an intraluminal $\mathrm{pH}$ below 5 which allows lipase inactivation, fatty acid partitioning and bile acid precipitation to interfere with solubilisation of dietary fat. Our studies were limited to the upper jejunum, but the classical studies of Borgström and colleagues ${ }^{6}$ indicated that the absorption of dietary fat begins in the duodenum and is completed in the proximal $100 \mathrm{~cm}$ of the jejunum, a conclusion supported by a recent authoritative review. ${ }^{34}$ Thus we were studying that part of the small intestine of most importance for digestion, solubilisation and absorption of dietary fat. In health, there is a large reserve function for these processes further down the small intestine. These studies form a baseline for comparison with diseased states (i) where this reserve function is reduced, as in the steatorrhoea that follows surgical resection of the ileum, (ii) where bile acid secretion may be reduced so that bile acid precipitation has a critical effect on aqueous phase bile acid concentration, again as in ileectomy steatorrhoea, (iii) where intraluminal $\mathrm{pH}$ may fall more often as in pancreatic exocrine insufficiency. ${ }^{33}$

We would like to thank the Cystic Fibrosis Trust for generously financing this project, and $\operatorname{Dr} M \quad R$ Boudry, $\mathrm{PhD}$, for assistance in the computerised analysis of the results. We are most grateful to Sister M E Gannon for assisting in the collection of 
samples. This study was presented at the Annual Meeting of the British Society of Gastroenterology 1979, and published in abstract form (Gut 1979; 20: A925).

\section{References}

1 Legg EF, Spencer AM. Studies on the stability of pancreatic enzymes in duodenal fluid to storage temperature and pH. Clin Chim Acta 1975; 65: 175-9.

2 Heizer WD, Cleaveland CR, Iber FL. Gastric inactivation of pancreatic supplements. Bull Johns Hopkins Hosp 1965; 116: 261-70.

3 Small DM. The physical chemistry of cholanic acids. In: Nair PP, Kritchevsky D, eds. The bile acids, vol. 1 (Chemistry). New York: Plenum Press, 1971: 289.

4 Borgström B. Partition of lipids between emulsified oil and micellar phases of glyceride-bile salt dispersions. J Lipid Res 1967; 8: 598-608.

5 Go VLW, Poley JR, Hofmann AF et al. Disturbances in fat digestion induced by acidic jejunal $\mathrm{pH}$ due to gastric hypersecretion in man. Gastroenterology 1970; 58: $638-46$.

6 Borgström B, Dahlqvist A, Lundh G et al. Studies of intestinal digestion and absorption in the human. J Clin Invest 1957; 36: 1521-36.

7 Worning $\mathrm{H}$, Müllertz S. pH and pancreatic enzymes in the human duodenum during digestion of a standard meal. Scand J Gastroenterol 1966; 1: 268-83.

8 Miller LJ, Malagelada J-R, Go VLW. Postprandial duodenal function in man. Gut 1978; 19: 699-706.

9 Rune SJ, Viskum K. Duodenal pH values in normal controls and in patients with duodenal ulcer. Gut 1969; 10: $569-71$.

10 Mansbach CM, Cohen RS. Leff PB. Isolation and properties of the mixed lipid micelles present in intestinal contents during lipid digestion in man. J Clin Invest 1975; 56: 781-91.

11 Hofmann AF, Borgström B. The intraluminal phase of fat digestion in man. J Clin Invest 1964; 43: 247-57.

12 Porter HP, Saunders DR. Isolation of the aqueous phase of human intestinal contents during the digestion of a fatty meal. Gastroenterology 1971; 60: 997-1007.

13 Hofmann AF. A physicochemical approach to the intraluminal phase of fat absorption. Gastroenterology 1966; 50: 56-64.

14 Cohen M, Morgan RJH, Hofmann AF. One-step qualitative extraction of medium-chain and long-chain fatty acids from aqueous samples. J Lipid Res 1969; 10: 614-6.

15 Iwata T, Yamasaki K. Enzymatic determination and thin-layer chromatography of bile acids in blood. J Biochem (Tokyo) 1964; 56: 424-31.

16 Wiggins HS. Simple method for estimating trypsin. Gut 1967; 8: 415-6.
17 Sigma Technical Bulletin No. 800. The titrimetric determination of lipase. Missouri, USA: Sigma Chemical Company, 1977.

18 Hyden S. A turbidimetric method for the determination of higher polyethylene glycols in biological materials. Ann Roy Agr Coll (Sweden) 1955; 22: 139-45.

19 Colquhoun D. Lectures on biostatistics 1st ed. London: Oxford University Press, 1971.

20 Bramwell-Cook H. Lennard Jones JE, Sherif SM et al. Measurement of tryptic activity in intestinal juice as a diagnostic test in pancreatic disease. Gut 1967; 8: 408-14.

21 Fields M, Duthie HL. Effect of vagotomy on intraluminal digestion of fat in man. Gut 1965; 6: 301-10.

22 Krone CL, Theoder E, Sleisenger MH et al. Studies on the pathogenesis of malabsorption. Lipid hydrolysis and micelle formation in the intestinal lumen. Medicine (Balt) 1968; 47: 89-106.

23 Thompson GR, Barrowman J, Gutierrez L et al. Action of neomycin in the intraluminal phase of lipid absorption. J Clin Invest 1971; 50: 319-23.

24 Ihse I. Arnesjö B. The phospholipase $\mathrm{A}_{2}$ content of human small intestinal contents. Acta Chem Scand 1973; 27: 2749-56.

25 Badley BWD, Murphy GM, Bouchier IAD et al. Diminished micellar phase lipid in patients with chronic nonalcoholic liver disease and steatorrhoea. Gastroenterology 1970; 58: 781-9.

26 DiMagno EP, Go VLW. Summerskill WHJ. Impaired cholecystokinin-pancreozymin secretion, intestinal dilution and malabsorption of fat in sprue. Gastroenterology 1972; 63: 25-32.

27 Longstreth GF. Malagelada J-R. Go VLW. The gastric response to a transpyloric duodenal tube. Gut 1975; 16: 777-80.

28 Malagelada J-R, Go VLW, Summerskill WHJ. Different gastric, pancreatic and biliary responses to solid-liquid or homogenized meals. Dig Dis Sci 1979; 24: $101-10$.

29 Cortot A, Phillips SF, Malagelada J-R. Gastric emptying of lipids after ingestion of a homogenized meal. Gastroenterology 1979; 76: 939-44.

30 Wiggins HS, Dawson AM. An Evaluation of unabsorbable markers in the study of fat absorption. Gut 1961; 2: 373-6.

31 Lanzini A, Bird R, Fitzpatrick WJF et al. Bile acid binding to dietary protein. [Abstract] Gut 1981; 22: A441.

32 Krag E, Phillips SF. Active and passive bile acid absorption in man - perfusion studies on the ileum and jejunum. J Clin Invest 1974; 53: 1686-94.

33 Regan PT, Malagelada J-R, DiMagno EP et al. Reduced intraluminal bile acid concentrations and fat maldigestion in pancreatic insufficiency: correction by treatment. Gastroenterology 1979; 77: 285-9.

34 Patton J. Gastrointestinal lipid digestion. In: Johnson LR ed. Physiology of the gastrointestinal tract. New York: Raven Press, 1981. 